\title{
BUTIA LALLEMANTII, UMA NOVA ARECACEAE DO BRASIL ${ }^{1}$ LEONARDO PAZ DEBLE ${ }^{2}$ JOSÉ NEWTON CARDOSO MARCHIORI ${ }^{3}$
}

\section{RESUMO}

É descrita e ilustrada Butia lallemantii Deble \& Marchiori, uma nova espécie, exclusiva dos campos arenosos do sudoeste sul-rio-grandense. Relacionada à Butia paraguayensis (Barb. Rodr.) L. H. Bailey, difere, desta, por ser desprovida de caule aéreo e pelo hábito cespitoso. A última característica serve para separá-la de Butia arenicola (Barb. Rodr.) Burret e de B. campicola (Barb. Rodr.) Noblick, espécies relacionadas, que ocorrem no Paraguai.

Palavras-chave: Butia, espécie nova, Arecaceae, Rio Grande do Sul, Brasil.

\begin{abstract} Rodr.) Noblick.

"Quando, de manhã, saí de Tapevi, a minha atenção foi despertada por uma planta grosseira de um cinzento brilhante que, em moitas herbáceas, cobria encostas inteiras, em milhares de exemplares. Apeei-me e encontrei inumeráveis palmeirinhas truncadas ou frondes de palmeiras que tinham todos os atributos da palmeira, menos o estipe, pois as folhas de um a dois pés de comprimento, pinatífidas como na maioria das palmeiras, saem diretamente do chão." (Avé-Lallemant, 1858).
\end{abstract}

A new species is described and illustrated: Butia lallemantii Deble \& Marchiori, native on sandy grasslands from south-western of Rio Grande do Sul State, Brazil. Butia lallemantii is allied to B. paraguayensis (Barb. Rodr.) L. H. Bailey, differing by its underground stalk and cespitose habit. The last character also serves to set it apart from other two related paraguayan species: B. arenicola (Barb. Rodr.) Burret and B. campicola (Barb.

Key words: Butia, new species, Arecaceae, Rio Grande do Sul, Brazil.

Nos campos arenosos do sudoeste sul-riograndense cresce um butiá desprovido de estipe, que forma populações de milhares de indivíduos. Sua abundância e aspectos peculiares chamam atenção dos que percorrem os campos de Alegrete, Manoel Viana e São Francisco de Assis.

Conhecida localmente como "butiá-anão" ou "butiazeiro-anão", os primeiros relatos dessa espécie devem-se a Robert Avé-Lallemant, médico alemão que excursionou pelo Rio Grande do Sul em meados do século XIX.
Em seu estudo sobre as palmeiras do Rio Grande do Sul, Mattos (1977) designou o material como Butia paraguayensis (Barb. Rodr.) Bailey, critério que foi seguido pela maioria dos trabalhos posteriores.

Marchiori, Elesbão \& Alvarez-Filho (1995) igualmente tratam a espécie sob este binômio, distinguindo-a de Butia yatay (Mart.) Becc. principalmente pela ausência de estipe ou pelo estipe curto (até 1,5 m). Posteriormente, Marchiori (2004), atribuiu às condições edáficas o porte de Butia paraguayensis, reconhecendo que a citada espécie pode expressar ecotipos ou aspectos taxonômicos ainda não definitivamente esclarecidos; totalmente acaule nos campos arenosos do sudoeste do estado, poderia apresentar estipe de até $6 \mathrm{~m}$, na região do Coatepe (Quaraí).

O estudo detalhado de numerosas populações, todavia, evidencia diferenças suficientes para separar estas espécies. Butia paraguayensis

1 Artigo recebido em 14/08/2005 e aceito para publicação em 10/11/2006.

${ }^{2}$ Biólogo, MSc., bolsista CAPES, doutorando do Programa de Pós-graduação em Engenharia Florestal, Centro de Ciências Rurais, Universidade Federal de Santa Maria, CEP97105-900, Santa Maria (RS).deble.biol@ gmail.com

3 Engenheiro Florestal, Dr., bolsista de Produtividade em Pesquisa do CNPq, Professor Titular do Departamento de Ciências Florestais, Universidade Federal de Santa Maria, CEP97105-900, Santa Maria (RS). balduinia@mail.ufsm.br 
apresenta caule solitário e aéreo, de até $2 \mathrm{~m}$, folhas com 40 pares de pinas, pecíolo com dentes ou espinhos curtos, intercalados com fibras, e frutos ovados, amarelo-esverdeados ou amarelos. Butia yatay apresenta estipe de 3-8 metros (até 15 metros em palmares de Entre Rios - Argentina), folhas com 60-70 pares de pinas, pecíolo armado de dentes espinescentes de até $3 \mathrm{~cm}$, e frutos ovados, distintamente apiculados no ápice. O “butiá-anão”, ao contrário destas espécies, é planta cespitosa, provida de 3-6 caules subterrâneos, com pecíolo de margens fibrosas e frutos ovado-lanceolados, amarelo-alaranjados, de ápice avermelhado.

\section{Descriptio}

Butia lallemantii Deble \& Marchiori, sp. nov. TIPO: BRASIL, Rio Grande do Sul, São Francisco de Assis, palmeira com copa hemisférica e aparentemente acaule, butiazal de centenas de indivíduos, em campos arenosos, L. P. Deble, A. S. de Oliveira \& J. N. C. Marchiori 1.514, 12.XII.2003. Holotypus SI.

Palmae caespitosae, haemisphericae, 70-130 cm altae. Caudex, 3-6, subterraneus, 30-70 cm longus. Folia pinnatisecta, brevi vaginata, $80-160 \mathrm{~cm}$ longa, petiolata. Petiolis fibrosis, 20-40 cm longis. Rachi linearia, 60-120 cm longa. Segmenta utrinque 25-35, in spatiis aequalibus $4-5 \mathrm{~cm}$, linearia vel filiformia, $18-45 \mathrm{~cm}$ longa, $0,5-2 \mathrm{~cm}$ lata. Spadix 28-50 cm; rachi $15-25 \mathrm{~cm}$, ramosi; rami $12-$ 28 , flexuosis, 8-25 cm longis. Spatha lignosa, acuta, glabra, extus fusca, intus castanea, 20-40 cm longa, 3-6 cm lata. Flores mascula lutea, 6-9 mm crassa. Flores feminei straminea, circa $10 \mathrm{~mm}$ longa. Drupa aurantiaca, apice rufescentia, ovato-lanceolata, 2,5-3,5 cm longa, 1,6-2,5 cm lata. Semen elliptica, circa $10 \mathrm{~mm}$ longa.

Planta cespitosa, de copa hemisférica, e 70$130 \mathrm{~cm}$ de altura (Figura 1a). Caules, 3-6, subterrâneos, de $30-70 \mathrm{~cm}$. Folhas pinadas, arqueadas, glabras, de $80-160 \mathrm{~cm}$ de comprimento (Figura 1b). Bainha curta e acinzentada, com margens providas de fibras achatadas e flexíveis; pecíolo indistinto da bainha, de $20-40 \mathrm{~cm}$, com margens fibrosas (Figura 1c); raque linear, de $60-120 \mathrm{~cm}, 25-35$-pinada; pinas distanciadas em 4-5 cm, dispostas em dois planos, lineares ou filiformes, de $18-45 \mathrm{~cm}$ de comprimento por 0,5-2 cm de largura. Inflorescências eretas; espádice esverdeado, de $28-50 \mathrm{~cm}$, com ramificações de até $25 \mathrm{~cm}$ (Figura 1d); raque de 15$25 \mathrm{~cm}$, composta por 12-28 raquilas primárias, flexuosas, de $8-25 \mathrm{~cm}$. Espata lenhosa, aguda, lisa, glabra, opaca na parte externa e castanha na interna, de $20-40 \mathrm{~cm}$ de comprimento por 3$6 \mathrm{~cm}$ de largura (Figura 1d). Flores masculinas, amarelas, de 6-9 $\mathrm{mm}$ de diâmetro, dispostas na metade superior das raquilas (Figura 1e). Flores femininas estramíneas, de cerca de $10 \mathrm{~mm}$, dispostas na base das raquilas (Figura 1f). Frutos ovado-lanceolados (2,5-3,5 cm de comprimento por 1,6-2,5 cm de largura), amarelo-alaranjados, de ápice avermelhado (Figura 1g). Sementes elípticas, com cerca de $10 \mathrm{~mm}$.

\section{Distribuição \& Habitat: Butia lallemantii} é exclusiva dos campos arenosos e areais no sudoeste do Rio Grande do Sul. Floresce no final da primavera e verão, e frutifica no verãooutono.

Comentários: Butia lallemantii demonstra relação com $B$. campicola, espécie paraguaia de hábito raramente cespitoso (então com 2-3 caules), que apresenta menor porte (cerca de $40 \mathrm{~cm}$ ) e frutos ovados, apiculados, de cor marrom-esverdeada.

Etimologia: O nome presta homenagem a Robert Avé-Lallemant, autor da mais antiga referência literária à espécie.

\section{BIBLIOGRAFIA}

Ave-Lallemant, R. Viagem pela província do Rio Grande do Sul (1858). Belo Horizonte: Ed. Itatiaia; São Paulo: Ed. da Universidade de São Paulo, 1980. 359p.

Marchiori, J. N. C. Fitogeografia do Rio Grande do Sul: campos sulinos. Porto Alegre, EST, 2004, 110p.

Marchiori, J. N. C. Vegetação e areais no sudoeste riograndense. Ciência \& Ambiente, v. 5, n. 11, p. 81-92, 1995.

Marchiori, J. N. C.; Elesbão, L. E. G.; Alvarez Filho, A. O Palmar do Coatepe. Ciência \& Ambiente, v. 5, n. 11, p. 93-104, 1995.

Mattos, J. R. Palmeiras do Rio Grande do Sul, Roessléria, Porto Alegre, v. 1, n. 1, p. 5-94, 1977. 


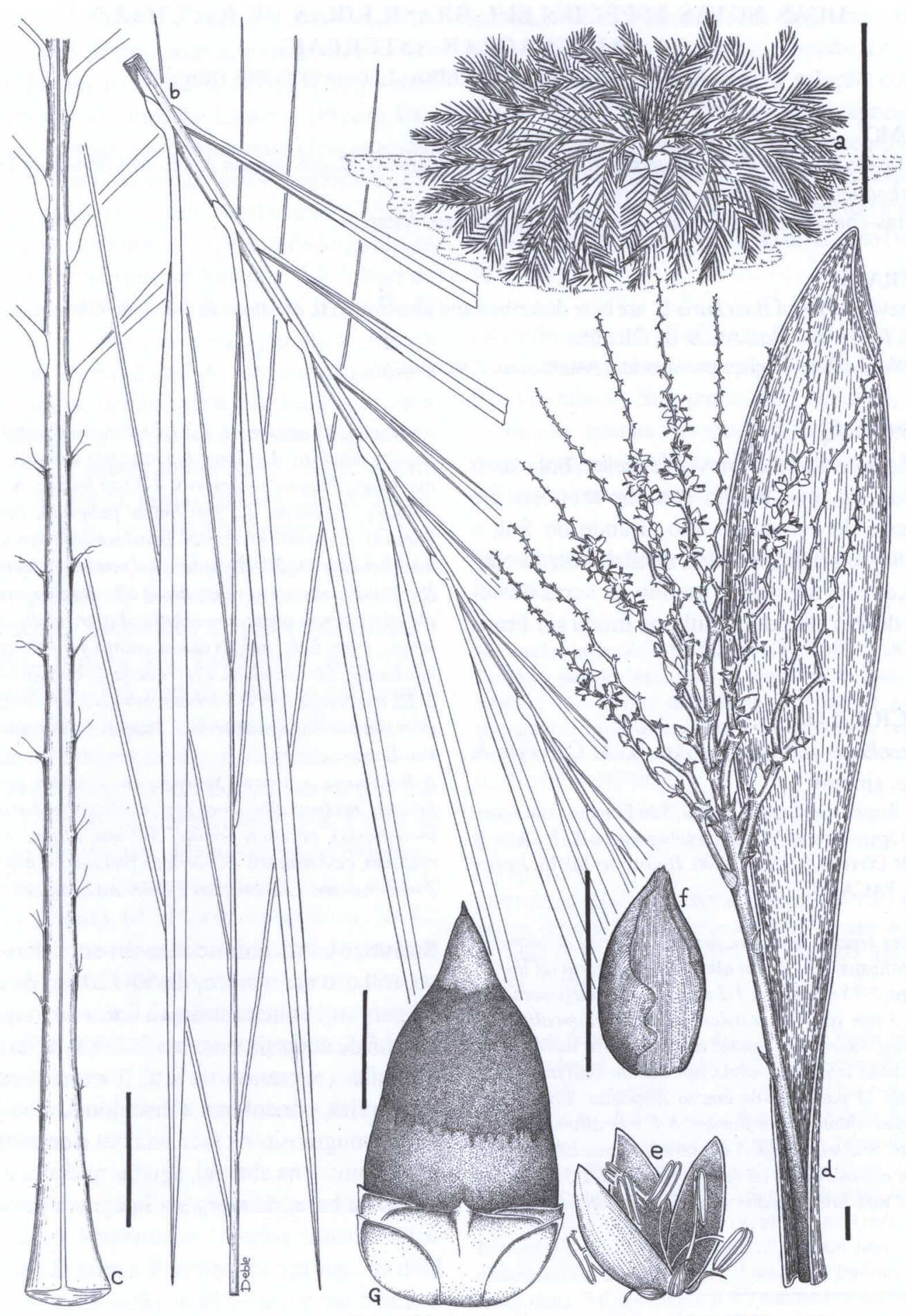

FIGURA 1 - Butia lallemantii Deble \& Marchiori, hábito (a). Folha (b). Pecíolo (c). Inflorescência e espata (d). Flor masculina (e). Flor feminina (f). Fruto (g). (L. P. Deble, A. S. de Oliveira \& J. N. C. Marchiori, 1.514). (a = $1 \mathrm{~m} ; \mathrm{b}, \mathrm{c}=5$ $\mathrm{cm} ; \mathrm{d}, \mathrm{e}, \mathrm{f}, \mathrm{g}=1 \mathrm{~cm})$. 